\title{
Investigation of in vitro and in vivo antioxidant and antidiabetic activities of Pinus halepensis extracts
}

\author{
Najoua Salhi $^{(\mathbb{1}}$, Abdelhakim Bouyahya $^{2^{*} \mathbb{D}}$, Otman El Guourrami $^{{ }^{\circledR}}$, Meryem El Jemli $^{\mathbb{1}}$, Ilhame Bourais $^{2^{(\mathbb{D}}}$, \\ Amina Zellou$^{1}$, Yahia Cherrah ${ }^{1}$, My El Abbes Faouzi ${ }^{1}$ \\ ${ }^{1}$ Laboratory of Pharmacology and Toxicology, Faculty of Medicine and Pharmacy, Mohammed V University in Rabat, Morocco \\ ${ }^{2}$ Laboratory of Human Pathologies Biology, Faculty of Sciences, Department of Biology, and Genomic Center of Human Pathologies, Faculty of Medicine \\ and Pharmacy, Mohammed V University in Rabat, Morocco \\ ${ }^{3}$ Laboratory of Analytical Chemistry and Bromatology, Faculty of Medicine and Pharmacy, Mohammed V University in Rabat, Morocco
}

\section{A R T I C L E I N F O}

Article Type:

Original Article

\section{Article History:}

Received: 27 April 2020

Accepted: 2 July 2020

\section{Keywords:}

Pinus halepensis

Enzyme inhibition

Anti-hyperglycemic

Antioxidant effect

\begin{abstract}
A B S T R A C T
Introduction: Pinus halepensis is a medicinal plant used in traditional medicine for treatment of various pathologies including diabetes. The objective of this study is to perform a phytochemical study and to evaluate the antioxidant and antidiabetic activities of extracts of the bark of $P$. halepensis.

Methods: Total polyphenols, flavonoids and tannins were determined by the Folin Ciocalteu method, aluminum trichloride reagent $\left(\mathrm{AlCl}_{3}\right)$ and vanillin assay. Evaluation of the antioxidant activity was carried out using 1,1-diphenyl-2-picrylhydrazyl (DPPH) and 2,2'-azinobis(3-ethylbenzothiazoline-6-sulfonic acid) (ABTS) and ferric reducing agent (ferric reducing). The antidiabetic activity was first revealed by enzymatic inhibition tests through measuring the residual activities of $\alpha$-amylase and $\alpha$-glucosidase, and then, by oral tolerance tests of glucose and starch in male Wistar rats. To verify the safety of plant extracts, acute oral toxicity was determined.

Results: The phytochemical analysis showed that the extracts of $P$. halepensis were rich in phenolic compounds. The anti-oxidation activity tests revealed a significant reducing power towards the radicals tested. In addition, $P$. halepensis inhibited the enzymes involved in diabetes ( $\alpha$-amylase and $\alpha$-glucosidase) at very low concentrations. These effects were verified in the in vivo approach, in particular by using the starch tolerance test.

Conclusion: P. halepensis extracts showed remarkable antioxidant and antidiabetic effects. However, further investigations are necessary to identify the main compounds of $P$. halepensis and to evaluate their antioxidant and antidiabetic effects.
\end{abstract}

Implication for health policy/practice/research/medical education:

Extracts of Pinus halepensis exhibited remarkable antioxidant and antidiabetic effects, which may have significant implications for the future development of antidiabetic drugs from $P$. halepensis.

Please cite this paper as: Salhi S, Bouyahya A, El Guourrami O, El Jemli M, Bourais I, Zellou A, et al. Investigation of in vitro and in vivo antioxidant and antidiabetic activities of Pinus halepensis extracts. J Herbmed Pharmacol. 2021;10(1):123-131. doi: 10.34172/jhp.2021.13.

\section{Introduction}

Recently, several studies have shown the importance of the identification of natural compounds from medicinal plants with antioxidant and antidiabetic activities. In Morocco, the traditional medicine revealed numerous medicinal species; which could be an important source for the discovery of antioxidant, anticancer, and antidiabetic drugs. Among these medicinal plants, Pinus halepensis (belonging to Pinaceae family) is mainly found in the coastal areas of the western Mediterranean region including
Morocco (1). This plant is used in Moroccan traditional medicine for the treatment of several diseases such as skin burn (2), against microbial infections and eczema (3), and against toothache (4). The chemical analysis of $P$. halepensis showed the presence of several chemical families such as terpenoids, polyphenols and flavonoids (5). These chemical compounds are known to exhibit numerous biological properties such as antimicrobial $(6,7)$, anticancer $(8,9)$, anti-inflammatory (9), antiparasitic, antioxidant and antidiabetic effects $(10,11)$. The 
management of diabetes, as one the major complicated diseases, involves several therapeutic strategies such as intestinal inhibition of enzymes involved in carbohydrates degradation (12). These enzymes include $\alpha$-amylase and a-glucosidase which degrade carbohydrates into simple sugars. Furthermore, the inhibition of these enzymes by natural products could be an alternative in diabetes treatment (13). Moreover, oxidative stress is implicated in the genesis of several diseases like diabetes. Thus, the combination between antioxidant and antidiabetic drugs is a promising strategy to prevent and treat the oxidative stress related diseases such as diabetes. Indeed, secondary metabolites of medicinal plants have shown several important antioxidant and antidiabetic effects $(14,15)$. $P$. halepensis organic extracts and its volatile compounds have shown several pharmacological effects such as antimicrobial, antioxidant, anti-hemolytic, genoprotective and anti-inflammatory activities (16-20). However, at the best of our knowledge, the bark extracts of this plant have not been studied for its antidiabetic and antioxidant effects. The aim of this study was to determine the phytochemical contents and to evaluate the antioxidant and antidiabetic effects of $P$. halepensis bark extracts.

\section{Materials and Methods}

Standards and reagents

$\rho$-Nitrophenyl-a-D-glucopyranoside

(pNPG), a-glucosidase from Saccharomyces cerevisiae, $\alpha$-amylase from Bacillus licheniformis, acarbose, Folin-Ciocalteu reagent, rutin, catechin, 1,1-diphenyl-2-picrylhydrazyl (DPPH), 2,2'-azinobis-(3-ethylbenzothiazoline-6-sulfonic acid) (ABTS), 6-hydroxy-2,5,7,8- tetramethylchroman-2carboxylic acid (Trolox), and ascorbic acid were purchased from Sigma-Aldrich (France). All other reagents and standards were of analytical reagent grade.

\section{Plant collection and extraction}

Barks of $P$. halepensis were collected from Khemisset Region (Morocco). The collected plant was authenticated at the Herbarium of Botany Department of the Scientific Institute of Rabat, Morocco (Voucher Specimen: RAB93519). The Barks (Figure 1) of the plant were dried at room temperature during one month; grounded into powder and then stored in glass brown bottle to preserve from light and moisture until use. For this study, two extracts (aqueous and ethanolic) were prepared. Briefly, for each extraction, $200 \mathrm{~g}$ of bark powder was macerated in one liter of the solvent (distilled water or absolute ethanol) under stirring in tightly closed bottles at room temperature for 24 hours. The extracts were filtered using a Buckner funnel and Whatman filter paper. Each filtrate was evaporated under vacuum using rotary evaporator at $50^{\circ} \mathrm{C}$. Aqueous and ethanolic extracts were lyophilized and stored at $4^{\circ} \mathrm{C}$ for further use. The yield of extract recorded was $4.31 \%$ and $4.92 \%$ for the aqueous and the ethanolic extracts, respectively.

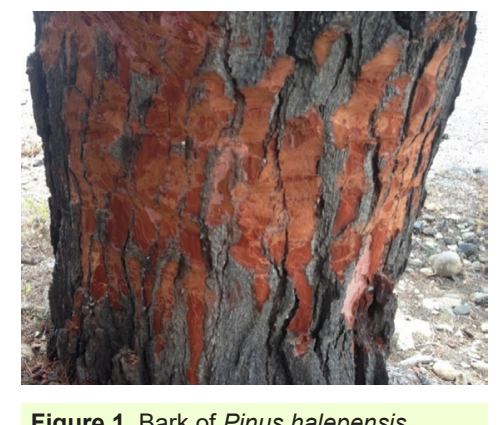

Figure 1. Bark of Pinus halepensis.

\section{Animals}

The animals used in this study were made up of rats and mice. For the acute oral toxicity test, nulliparous and nonpregnant Swiss mice, 2 to 2.5 months old and weighing between 24 and 36 g were used. For glucose and starch tolerance tests, male Wistar rats aged between 3 to 4 months and weighing between 150 and $200 \mathrm{~g}$ were used. The animals obtained from the pet store at the Faculty of Science in Kenitra were housed in cages and acclimated 2 weeks before the start of the experiment, at a temperature of $22^{\circ} \mathrm{C}( \pm 3)$, at a relative humidity between $30 \%$ and $70 \%$, and subjected to a light/dark cycle of $12 / 12$ hours. During this period, the animals had free access to food and water. The used protocol was received the approval of a commission from the Animal Experimentation Ethics Committee of the Faculty of Medicine and Pharmacy of Rabat (FMPR). Moreover, the experimenters who practiced animal experimentation complied with the ethical rules applicable in this area.

\section{Evaluation of acute oral toxicity study}

Acute oral toxicity of $P$. halepensis extracts was carried out on Swiss female mice according to the limit test of the OECD 423 guideline at a dose level of $2000 \mathrm{mg} /$ $\mathrm{kg}$ body weight using two steps (three rats in each step). After fasting overnight, three mice were received single oral dose of $2000 \mathrm{mg} / \mathrm{kg}$ body weight (BW). The animals were observed for gross behavioral, neurological, autonomic and toxic signs for 5 hours after extracts/ vehicle administration and daily for 2 weeks. Food consumption and body weight were recorded daily for 14 days. Untreated control group receiving distilled water as vehicle was also assayed. As no toxic signs were observed, a second test was prepared containing a group of three rats treated at 48 hours intervals with the same dose for the confirmation.

\section{Phytochemical study \\ Total phenolic content}

Phenolic contents of $P$. halepensis extracts were determined by using the Folin-Ciocalteu reagent (21). A standard curve was evaluated using gallic acid concentrations ranging from 0.975 to $125 \mu \mathrm{g} / \mathrm{mL}$. Firstly, $2.5 \mathrm{~mL}$ of $10 \%$ $(\mathrm{v} / \mathrm{v})$ of Folin-Ciocalteu reagent was mixed with $0.5 \mathrm{~mL}$ 
of sample solution. The reaction was incubated at $45^{\circ} \mathrm{C}$ for 30 minutes after the addition of $4 \mathrm{~mL}$ of $7.5 \%(\mathrm{w} / \mathrm{v})$ $\mathrm{Na}_{2} \mathrm{CO}_{3}$. The absorbance against blank was determined at $765 \mathrm{~nm}$. TPCs were expressed as gallic acid equivalents per gram of dry weight of extract (mg GAE/g extract).

\section{Total flavonoid content}

TFC of $P$. halepensis extracts were determined as described by Dewanto et al (22). Briefly, $1 \mathrm{~mL}$ of the sample was added to 7.4 of distilled water and $0.3 \mathrm{~mL}$ of $\mathrm{NaNO}_{3}(5 \%)$. Then, $0.3 \mathrm{~mL}$ of $\mathrm{AlCl}_{3}(10 \% \mathrm{w} / \mathrm{v})$ was added 5 minutes later. After 6 minutes of incubation, $2 \mathrm{~mL}$ of $\mathrm{NaOH}(1 \mathrm{M})$ was added and this solution was mixed well and allowed to stand for 30 minutes at room temperature. The absorbance was measured against a blank at $510 \mathrm{~nm}$. Calibration curve was established using Rutin as a standard in the range of $6.25-500 \mu \mathrm{g} / \mathrm{mL}$. The flavonoid content was expressed as Rutin equivalent per gram of extract dry weight (mg RE/g edw).

\section{Total tannin content}

Tanin contents were determined by the method described by Julkunen-Tiitto et al (23). Briefly, an aliquot (50 $\mu \mathrm{L})$ of each extract or standard solution was mixed with $1.5 \mathrm{~mL}$ of $4 \%$ vanillin (prepared with $\mathrm{MeOH}$ ), then $750 \mu \mathrm{L} \mathrm{HCl}$ $(12 \mathrm{M})$ was added. The well-mixed solution was incubated at ambient temperature in the dark for $20 \mathrm{~min}$. The absorbance was read at $500 \mathrm{~nm}$. Catechin (12.5-1000 $\mu \mathrm{g} /$ $\mathrm{mL}$ ) was used to make the standard curve and the results were expressed as mg of Catechin equivalents per gram of dry weight extract (mg CE/g edw).

\section{Antioxidant activity}

\section{DPPH radical scavenging activity assay}

Radical scavenging activity of the extracts was measured using the stable radical DPPH as described by Huang et al (24). A solution of DPPH (0.2 mM) was prepared, and 0.5 $\mathrm{mL}$ of this solution was mixed with $2.5 \mathrm{~mL}$ of the extracts $(0.5-8 \mu \mathrm{g} / \mathrm{mL})$. The reaction mixture was vortexed thoroughly and left in the dark for 30 minutes at room temperature. The absorbance of the mixture was measured at $517 \mathrm{~nm}$ in a spectrophotometer and the results were expressed as Trolox equivalent from the calibration curve, which ranged from 0.25 to $5 \mu \mathrm{g} / \mathrm{mL}$. The percentage of scavenging activity was expressed as:

DPPH scavenging effect $(\%)=((A 0-A 1) / A 0) \times 100)$

Where: $A_{0}$ : absorbance of the control and $A_{1}$ : absorbance of the sample solution or standard.

Scavenging activity in this assay was expressed as $\mathrm{IC}_{50}$, which represents the concentration of the extract required to inhibit $50 \%$ of the free radical scavenging activity.

\section{ABTS radical scavenging assay}

The ability of our extracts to scavenge the ABTS radical was determined according to a previously described method (25). A solution of ABTS radical cation $\left(\mathrm{ABTS}^{+}\right)$ was prepared by the reaction between $10 \mathrm{~mL}$ of $2 \mathrm{mM}$ ABTS in $\mathrm{H}_{2} \mathrm{O}$ and $100 \mu \mathrm{L}$ of $70 \mathrm{mM}$ potassium persulphate at room temperature in the dark for 24 hours. The $\mathrm{ABTS}^{++}$ solution was then diluted with methanol to obtain absorbance of 0.70 at $734 \mathrm{~nm}$. Samples and standard were prepared at the concentration range of $2.5-50 \mu \mathrm{g} / \mathrm{mL}$, $10-70 \mu \mathrm{g} / \mathrm{mL}$ and $2.5-50 \mu \mathrm{g} / \mathrm{mL}$ for ethanolic, aqueous extracts and Trolox, respectively. The tests were essayed in triplicate by diluting $200 \mu \mathrm{L}$ of extracts (or standard) in $2 \mathrm{~mL}$ of the $\mathrm{ABTS}^{+}$solution diluted with methanol and allowed to react for 1 minute. The absorbance was recorded on a spectrophotometer at $734 \mathrm{~nm}$. The percentage of scavenging activity was determined by the following formula.

$\%$ of scavenging effect $=((A 0-A 1) / A 0) \times 100$

Where: $A 0$ : absorbance of the control, $A 1$ : absorbance of the sample solution or standard,

$\mathrm{IC}_{50}$ values were determined by modeling the concentration versus the $\%$ of inhibition.

\section{Ferric reducing antioxidant power assay (FRAP)}

Antioxidant activities of $P$. halepensis extracts were also tested by the FRAP method as previously described by Oyaizu et al (26) with some modifications. Ascorbic acid was used as standard to establish the calibration curve at the concentration range of $3.906-125 \mu \mathrm{g} / \mathrm{mL}$. In briefly, $2.5 \mathrm{~mL}$ of $0.2 \mathrm{M}$ phosphate buffer $(\mathrm{pH}=6.6)$ was added to $1 \mathrm{~mL}$ of sample and mixed with $2.5 \mathrm{~mL}$ of potassium ferricyanide solution (1\%). Then, $2.5 \mathrm{~mL}$ of trichloroacetic acid $(10 \%)$ was added to the mixture after an incubation time of $20 \mathrm{~min}$ at $50^{\circ} \mathrm{C}$. Then, the mixture was centrifuged for 10 minutes $(3000 \mathrm{rpm})$. Finally, mixture of $2.5 \mathrm{~mL}$ of distilled water and $0.5 \mathrm{~mL} \mathrm{FeCl}_{3}$ solution $(0.1 \%, \mathrm{w} / \mathrm{v})$ was added to $2.5 \mathrm{~mL}$ of the supernatant. Measurement was done using spectrophotometer. FARP antioxidant activities were expressed as ascorbic acid equivalent per gram of extract dry weight (mg AAE/g edw).

\section{In vitro antidiabetic activity}

$\alpha$-Amylase inhibition assay

The a-amylase inhibitory of $P$. halepensis extracts was evaluated according to the protocol of Tadera et al (27) with some modifications. Briefly, a mixture of $50 \mu \mathrm{L}$ of samples, $180 \mu \mathrm{L}$ of phosphate buffer $(\mathrm{pH} 6.7 ; 0.02 \mathrm{M}$; $6 \mathrm{mM} \mathrm{NaCl})$, and $20 \mu \mathrm{L}$ of enzyme $\alpha$-amylase $(0.3 \mathrm{U} /$ $\mathrm{mL}$ ) was incubated at $37^{\circ} \mathrm{C}$ for 3 minutes. Then, $250 \mu \mathrm{L}$ of $0.2 \%$ starch solution (enzyme substrate) prepared in phosphate buffer $(\mathrm{pH}=6.7)$ was added to the reacting mixture. Therefore, the reaction mixture was incubated at $37^{\circ} \mathrm{C}$ for 15 minutes. Thereafter, $400 \mu \mathrm{L}$ of $\mathrm{HCl}(1 \mathrm{M})$ and $500 \mu \mathrm{L}$ of Iodine $(5 \mathrm{mM})$ were added to the mixture and the absorbance was measured at $630 \mathrm{~nm}$ using UV- 
Vis spectrophotometer. Acarbose was used as positive control. The percentage of inhibition was calculated by the followed formula.

$\%$ of inhibition $=\left(\left(\mathrm{Abs}_{\text {sub }}-\mathrm{Abs}_{\text {enz+sub }}\right)-\left(\mathrm{Abs}_{\text {control }}-\mathrm{Abs}\right.\right.$ sample $\left.)) /\left(\mathrm{Abs}_{\text {sub }}-\mathrm{Abs}_{\text {enz }+ \text { sub }}\right)\right) * 100$

Where:

Abs ${ }_{\text {enz }+ \text { sub }}$ : the absorption of positive control (substrate with enzyme)

Acb $_{\text {sub }}$ : The absorption of negative control (substrate without enzyme)

As: The absorption of the samples (substrate with sample and enzyme)

Asb: The absorption of substrate and sample without enzyme.

Acarbose was used as a positive control. Moreover, the $\mathrm{IC}_{50}$ values (inhibitor concentration necessary to inhibit $50 \%$ of the activity enzyme) were determined using the law equation by modulating the inhibition percentages versus the concentrations.

\section{$\alpha$-Glucosidase inhibition assay}

The a-glucosidase inhibition activities of $P$. halepensis extracts were tested using the enzymatic activity measured at $405 \mathrm{~nm}$ by monitoring hydrolysis of $p$ NPG and the results were expressed as $\mathrm{IC}_{50}$ values. Briefly, $100 \mu \mathrm{L}$ of sodium phosphate buffer $(0.1 \mathrm{M}, \mathrm{pH} 6.7)$ containing the $0.1 \mathrm{U} / \mathrm{mL}$ a-glucosidase enzyme, were preincubated with $150 \mu \mathrm{L}$ of the sample at $37^{\circ} \mathrm{C}$ for 10 minutes. $200 \mu \mathrm{L}$ of $1 \mathrm{mM} p \mathrm{NPG}$ solution was added to the enzymatic solution containing extract, and the reaction mixture was incubated at $37^{\circ} \mathrm{C}$ for 30 minutes. In this assay, acarbose was also used as positive control. The percentage of inhibition was calculated by the followed formula.

$\%$ of inhibition $=\left(\left(\mathrm{Abs}_{\text {sub }}-\mathrm{Abs}_{\text {enz }+ \text { sub }}\right)-\left(\mathrm{Abs}_{\text {control }}-\mathrm{Abs}\right.\right.$ sample $)) /\left(\right.$ Abs $\left.\left._{\text {sub }}-\mathrm{Abs}_{\text {enz }+ \text { sub }}\right)\right) * 100$

Where:

Abs ${ }_{\text {enz }+ \text { sub }}$ : the absorption of positive control (substrate with enzyme)

Acb $_{\text {sub }}$ : The absorption of negative control (substrate without enzyme)

As: The absorption of the samples (substrate with sample and enzyme)

Asb: The absorption of substrate and sample without enzyme.

Acarbose was used as a positive control. Moreover, the $\mathrm{IC}_{50}$ values (inhibitor concentration necessary to inhibit $50 \%$ of the activity enzyme) were determined using the law equation by modulating the inhibition percentages versus the concentrations.

In vivo antidiabetic activity

Oral glucose tolerance test (OGTT)

On six samples of non-diabetic rats, $P$. halepensis extracts were administered by gavage at two doses of 250 and 500 at $\mathrm{mg} / \mathrm{kg}$. A group of animals were given metformin (300 $\mathrm{mg} \mathrm{mg} / \mathrm{kg}$ ). The animals of control group were given orally equal volume of water only. After 10 minutes, animals were administered orally with Glucose at a dose of $3 \mathrm{mg} / \mathrm{kg}$. Blood samples were collected from the tail vein at $0,30,60,90,120$, and 150 minutes. Total glycemic responses to OGTT were calculated from respective areas under the curves (AUC) of glycaemia during the 150 minutes observation period. The variation of glycaemia was defined as the difference between glycaemia at $t_{0}$ and a following time point.

Blood glucose concentrations were recorded and AUC determined. The maximum blood glucose concentration found during blood glucose determination was taken as the peak blood glucose. The formula used for AUC determination was as follows:

$$
\begin{aligned}
\operatorname{AUC}\left(\frac{\mathrm{mg}}{\mathrm{dL} * \mathrm{H}}\right)= & \frac{(\mathrm{G} 0+\mathrm{G} 30)}{2} \times(\mathrm{T} 30-\mathrm{T} 0)+\frac{(\mathrm{G} 30+\mathrm{G} 60)}{2} \times(\mathrm{T} 60-\mathrm{T} 30) \\
& +\frac{(\mathrm{G} 60+\mathrm{G} 90)}{2} \times(\mathrm{T} 90-\mathrm{T} 60)+\frac{(\mathrm{G} 90+\mathrm{G} 120)}{2} \times(\mathrm{T} 120-\mathrm{T} 90) \\
& +\frac{(\mathrm{G} 120+\mathrm{G} 150)}{2} \times(\mathrm{T} 150-\mathrm{T} 120)
\end{aligned}
$$

\section{Oral starch tolerance test (OSTT)}

On six samples of non-diabetic rats, $P$. halepensis extracts were administered by gavages at doses of 250 and 500 $\mathrm{mg} / \mathrm{kg}$. A group of animals were given acarbose $(10 \mathrm{mg} /$ $\mathrm{kg}$ ). The animals of control group were given orally equal volume of water only. After 10 minutes, animals were administered orally with Starch at a dose of $3 \mathrm{mg} / \mathrm{kg}$. Blood samples were collected from the tail vein at $0,30,60,90$, 120 , and 150 minutes. Total glycemic responses to OSTT were also calculated from respective AUC of glycaemia during the 150 minutes observation period. Blood glucose concentrations were recorded and AUC determined. The maximum blood glucose concentration found during blood glucose determination was taken as the peak blood glucose. The formula for AUC determination was as follows:

$$
\begin{aligned}
\operatorname{AUC}\left(\frac{\mathrm{mg}}{\mathrm{dL} * \mathrm{H}}\right)= & \frac{(\mathrm{G} 0+\mathrm{G} 30)}{2} \times(\mathrm{T} 30-\mathrm{T} 0)+\frac{(\mathrm{G} 30+\mathrm{G} 60)}{2} \times(\mathrm{T} 60-\mathrm{T} 30) \\
& +\frac{(\mathrm{G} 60+\mathrm{G} 90)}{2} \times(\mathrm{T} 90-\mathrm{T} 60)+\frac{(\mathrm{G} 90+\mathrm{G} 120)}{2} \times(\mathrm{T} 120-\mathrm{T} 90) \\
& +\frac{(\mathrm{G} 120+\mathrm{G} 150)}{2} \times(\mathrm{T} 150-\mathrm{T} 120)
\end{aligned}
$$

Statistical analysis

Data were expressed as the mean values \pm standard deviation (SD) for each measurement. The data were also analyzed by one-way analysis of variance (ANOVA). Post hoc procedure was used for significance of difference $(P$ $<0.05)$.

\section{Results}

Total phenolic, flavonoid, and tannin contents

The bark of $P$. halepensis had an extraction rate of $4.31 \%$ 
for the aqueous extract and $4.92 \%$ for the ethanolic extract. The contents of total polyphenols, flavonoids, and condensed tannins were determined from the calibration curves $\left(y=0.0974 x+0.0244 ; \quad R^{2}=1\right), \quad(y=0.0116 x+0.0057$; $\left.\mathrm{R}^{2}=0.9999\right)$, and $\left(\mathrm{y}=0.0344 \mathrm{x}-0.0045 ; \mathrm{R}^{2}=0.9963\right)$ plotted using standard gallic acid, rutin, and catechin, respectively. Total phenolic, flavonoid, and tannins contents of $P$. halepensis ethanol (PHEE) and aqueous (PHAE) extracts are summarized in Table 1.

Generally, it can be noted that the two aqueous and ethanolic extracts contained an important source of phenolic compounds. Indeed, the phenolic contents in PHEE and PHAE were respectively $423.51 \pm 1.14$ and $401.85 \pm 3.26 \mathrm{mg} \mathrm{GAE} / \mathrm{g}$ of extract. In addition, the flavonoid contents of the PHEE and the PHAE were respectively $865.40 \pm 12.10$ and $738.97 \pm 1.39 \mathrm{mg} \mathrm{RE} / \mathrm{g}$ of extract. Extracts of $P$. halepensis also contained significant tannin contents with $332.97 \pm 9.64 \mathrm{mg} \mathrm{CE} / \mathrm{g}$ of extract for PHEE and $529.98 \pm 13.46 \mathrm{mg} \mathrm{CE} / \mathrm{g}$ of extract for PHAE.

Antioxidant activity

The antioxidant activities of $P$. halepensis ethanol and aqueous extracts were evaluated using three complementary methods: DPPH and ABTS radical scavenging capacity, and FRAP. The results are summarized in Table 2. As listed, ethanol and aqueous extracts showed important antioxidant effects. Ethanolic and the aqueous of $P$. halepensis presented significant free radical neutralization capacities, with $\mathrm{IC}_{50}$ values of $3.28 \pm 0.37$ and $3.1 \pm 0.42 \mu \mathrm{g} / \mathrm{mL}$ respectively for $\mathrm{DPPH}$ and $3.26 \pm 0.59$ and $3.59 \pm 0.62 \mu \mathrm{g} / \mathrm{mL}$ for ABTS.

These results do not show any significant difference between the two extracts tested. By comparing the antioxidant capacity of the extracts with that of Trolox to reduce DPPH $(2.42 \pm 0.18 \mu \mathrm{g} / \mathrm{mL})$ and ABTS $(2.61 \pm 0.34$ $\mu \mathrm{g} / \mathrm{mL})$, it was noted that there was a significant difference between the two extracts and Trolox $(P<0.05)$ used as a standard antioxidant for the two methods used. Moreover, PHEE exhibited an advantageous iron-reducing power, with an $\mathrm{IC}_{50}$ of $16.56 \pm 0.043 \mu \mathrm{g} / \mathrm{mL}$ and of $20.80 \pm 0.334$ $\mu \mathrm{g} / \mathrm{mL}$, respectively. These results showed a significant difference $(P<0.05)$ between the two tested extracts. The reducing power of the two extracts showed a lower effect compared with ascorbic acid which showed an $\mathrm{IC}_{50}=5.67 \pm 0.049 \mu \mathrm{g} / \mathrm{mL}$. These results revealed a significant difference $(P<0.05)$ between the extracts and the ascorbic acid used as standard.
In vitro antidiabetic effect

In vitro antidiabetic effect of $P$. halepensis ethanol and aqueous extracts was carried out by enzymatic inhibition of $\alpha$-amylase and $\alpha$-glucosidase. The resultants obtained was expressed as $\mathrm{IC}_{50}$ (Table 3 ).

As showed, ethanol extract exhibited more inhibitory effect on $\alpha$-glucosidase and $\alpha$-Amylase activities comparing to aqueous extract. Indeed, ethanol extract showed an important inhibition of $\alpha$-amylase $\left(\mathrm{IC}_{50}=234.26 \pm 12.23\right.$ $\mu \mathrm{g} / \mathrm{mL})$ and $a$-glucosidase $\left(\mathrm{IC}_{50}=7.97 \pm 0.53 \mu \mathrm{g} / \mathrm{mL}\right)$. Moreover, aqueous extract inhibited a-amylase and $\alpha$-glucosidase at $\mathrm{IC}_{50}=1196.38 \pm 11.80$ and $\mathrm{IC}_{50}=9.37 \pm 0.41$ $\mu \mathrm{g} / \mathrm{mL} . \quad \mathrm{IC}_{50}$ values of PHEE and PHAE extracts were lower than those showed by acarbose (positive control) which inhibited $\alpha$-amylase and $\alpha$-glucosidase at $\mathrm{IC}_{50}=311.20 \pm 1.38$ and $\mathrm{IC}_{50}=18.0 \pm 2.00 \mu \mathrm{g} / \mathrm{mL}$, respectively.

In vivo antidiabetic effect

Oral glucose tolerance test

The results of the effect of PHAE and PHEE extracts at

Table 2. Antioxidant activity of the different parts of the plant determined by DPPH, ABTS and FRAP assays

\begin{tabular}{llll}
\hline Extracts & DPPH & ABTS & FRAP \\
\hline PHAE & $3.28 \pm 0.37^{\mathrm{a}}$ & $3.59 \pm 0.62^{\mathrm{a}}$ & $20.80 \pm 0.334^{\mathrm{a}}$ \\
PHEE & $3.1 \pm 0.42^{\mathrm{a}}$ & $3.26 \pm 0.59^{\mathrm{a}}$ & $16.56 \pm 0.043^{\mathrm{b}}$ \\
Trolox & $2.42 \pm 0.18^{\mathrm{b}}$ & $2.61 \pm 0.34^{\mathrm{b}}$ & - \\
Ascorbic acid & - & - & $5.67 \pm 0.049^{\mathrm{c}}$ \\
\hline
\end{tabular}

Different letters indicate the significant difference $(P<0.05)$ between aqueous extract, ethanolic extract and acarbose on the same column. Data are reported to mean $(\mathrm{n}=3) \pm$ SD. Abbreviations: PHAE, $P$. halepensis aqueous extract; PHEE, P. halepensis ethanolic extract.

Table 3. Enzymatic inhibition $\left(\mathrm{IC}_{50}\right.$ values $\left.(\mu \mathrm{g} / \mathrm{mL})\right)$ of $P$. halepensis extracts against $\alpha$-amylase and $\alpha$-glucosidase

\begin{tabular}{lll}
\hline Extracts & $\boldsymbol{\alpha}$-Glucosidase & $\boldsymbol{\alpha}$-Amylase \\
\hline PHAE & $9.37 \pm 0.41^{*}$ & $1196.38 \pm 11.80^{* * *}$ \\
PHEE & $7.97 \pm 0.53^{*}$ & $234.26 \pm 12.23^{*}$ \\
Acarbose & $18.01 \pm 2.00^{* *}$ & $311.20 \pm 1.38^{* *}$ \\
\hline
\end{tabular}

Abbreviations: $\mathrm{PHAE}, P$. halepensis aqueous extract; $\mathrm{PHEE}, P$. halepensis ethanolic extract.

* Indicates the significant difference $(P<0.05)$ between aqueous extract, ethanolic extract and acarbose on the same column. Data are reported to mean $(n=3) \pm S D$.

Table 1. Total phenol and flavonoid contents of $P$. halepensis extracts

\begin{tabular}{lcccc}
\hline Extracts & Yield of extraction \% & TPC (mg EAG/ g extrait) & TFC (mg ER/g extrait) & TTC (mg EC/g extrait) \\
\hline PHAE & 4.31 & $401.85 \pm 3.26$ & $738.97 \pm 1.39$ \\
PHEE & 4.92 & $423.51 \pm 1.14$ & $865.40 \pm 12.10$ & $332.97 \pm 9.64 \mathrm{mg}$ \\
\hline
\end{tabular}

TPC: total phenolic content, TFC: total flavonoid content, TCC: total condensed tannins,

mg RE/g extract: mg of Rutin equivalent per gram of extract, mg GAE/g extract: mg Galic Acid equivalent per gram of extract, mg CE/g extract: mg Catechin equivalent per gram of extract. 
doses of 250 and $500 \mathrm{mg} / \mathrm{kg}$ and of Metformin at the dose of $300 \mathrm{mg} / \mathrm{kg}$, on the monitoring of blood glucose levels of normal rats subjected to an oral glucose tolerance test, are shown in Figure 2. After an oral glucose load, a statistically significant hyperglycemia was detected 30 min after all the animals were force-fed with glucose. This hyperglycemia tended to decrease over time for all treated groups. Analysis of the glucose monitoring curves (Figure 2) showed a reduction in blood sugar over time by the different products tested compared to normal saline (control batch). This reduction was lower for the batch treated with the aqueous extract and greater for the batches treated with the ethanolic extract at the dose of 500 $\mathrm{mg} / \mathrm{kg}$ and with Metformin. The study of the effect of the various substances tested on the maximum blood sugar level (G Max) and on the AUC in the glucose tolerance test are shown in Table 4.

The batches of the rats treated with the aqueous extract at the doses of 250 and $500 \mathrm{mg} / \mathrm{kg}$ and with the ethanolic extract at the dose of $250 \mathrm{mg} / \mathrm{kg}$ did not show any significant reduction $(P<0.05)$ in $\mathrm{G}$ Max and AUC levels (Table 4) compared to the batch of control rats. The ethanolic extract at a dose of $500 \mathrm{mg} / \mathrm{kg}$ significantly $(P<0.05)$ lowered the two parameters studied compared to the control batch. Metformin also succeeded in significantly reducing $(P<0.05)$ G Max and AUC with the lowest values (Table 4 ).

The results of the evolution of starch tolerance in normoglycemic rats treated with acarbose and with the different extracts of the bark of $P$. halepensis are shown in Figure 3. After an oral starch load, a statistically significant hyperglycemia was detected in the control group $30 \mathrm{~min}$ after force-feeding the animals, tending to decrease over time. Acarbose was effective and significantly inhibited the hyperglycemia observed in control rats from the start of the experiment and throughout the experimental period. The different extracts of the bark of $P$. halepensis at
Table 4. Effect of aqueous and ethanolic extract of $P$. halepensis bark and Metformin on AUC and G Max after hyperglycemia caused by administration of glucose in normoglycemic rats

\begin{tabular}{lcc}
\hline & AUC $\left(\mathrm{mg} /\left(\mathrm{dL}^{*} \mathrm{~h}\right)\right.$ & $\mathrm{G} \mathrm{Max}(\mathrm{mg} / \mathrm{dL})$ \\
\hline Control & $295.29 \pm 5.17^{\mathrm{c}}$ & $140,33 \pm 2,73^{\mathrm{c}}$ \\
Metformine $(300 \mathrm{mg} / \mathrm{kg})$ & $232.88 \pm 11.65^{\mathrm{a}}$ & $103,83 \pm 3,66^{\mathrm{a}}$ \\
PHAE $(250 \mathrm{mg} / \mathrm{kg})$ & $291.63 \pm 12.74^{\mathrm{c}}$ & $133,17 \pm 4,54^{\mathrm{c}}$ \\
PHAE $(500 \mathrm{mg} / \mathrm{kg})$ & $280.71 \pm 6.76^{\mathrm{c}}$ & $124,33 \pm 2,79^{\mathrm{c}}$ \\
PHEE $(250 \mathrm{mg} / \mathrm{kg})$ & $274.88 \pm 8.58^{\mathrm{c}}$ & $124,17 \pm 7,53^{\mathrm{c}}$ \\
PHEE $(500 \mathrm{mg} / \mathrm{kg})$ & $261.92 \pm 24.72^{\mathrm{b}}$ & $114,00 \pm 10,86^{\mathrm{b}}$ \\
\hline
\end{tabular}

Abbreviations: G Max, maximum blood sugar level; AUC, area under the curve; $\mathrm{PHAE}, P$. halepensis aqueous extract; $\mathrm{PHEE}, P$. halepensis ethanolic extract.

Different letters indicate the significant difference $(P<0.05)$ between aqueous extract, ethanolic extract and acarbose on the same column. Data are reported to mean $(n=3) \pm S D$.

different doses showed a remarkable anti-hyperglycemic effect compared to acarbose. Indeed, in addition to the total inhibition of hyperglycemia, the extracts produced a slight drop in blood sugar levels initially found. The importance of this decrease was greater in batches treated with ethanolic extract and in correlation with the concentration of extracts. The study of the effect of the different substances tested on the G Max and on the AUC in the starch tolerance test are shown in Table 5.

The batches of the rats treated with ethanolic extract and aqueous extract at different doses (250 and $500 \mathrm{mg}$ / $\mathrm{kg}$ ) and the batch treated with acarbose at a dose of 10 $\mathrm{mg} / \mathrm{kg}$ showed G Max values significantly $(P<0.05)$ lower than that of the control rat group. For the AUC results, the two extracts at the different doses showed the lowest values with a significant difference $(P<0.05)$ compared to the control batch. Acarbose also showed AUC values significantly lower than that of the control batch but significantly higher than that of the batches treated with the two extracts at different doses.

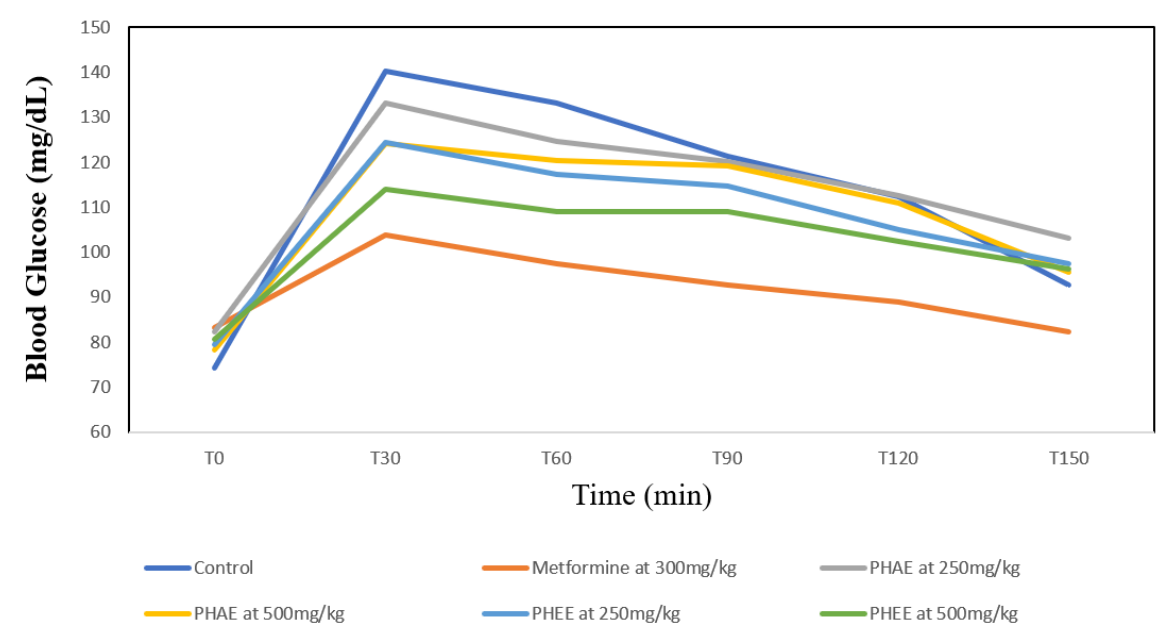

Figure 2. Blood glucose response during oral glucose tolerance test in normal rats treated with $P$. halepensis extracts and metformine. Abbreviations: PHAE, P. halepensis aqueous extract; PHEE, P. halepensis ethanolic extract. 


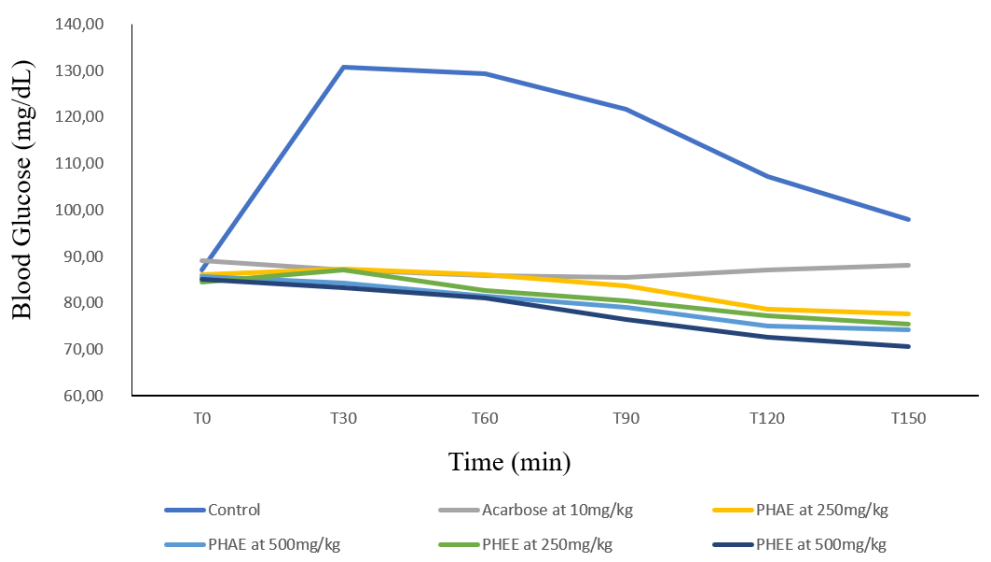

Figure 3. Blood glucose response during oral starch tolerance test in normal rats treated with $P$. halepensis extracts and Acarbose. Abbreviations: PHAE, P. halepensis aqueous extract; PHEE, P. halepensis ethanolic extract.

Toxicological investigation

Data obtained showed that $2000 \mathrm{mg} / \mathrm{kg}$ concentration of $P$. halepensis aqueous and ethanol extracts didn't induce any related signs of toxicity or mortality, during the 14 days of study, in all tested animals of each group. The treatment by each extract did not show a weight loss or changes in the behavioral pattern or any undesired pathologic changes of the animals. Therefore, the oral $\mathrm{LD}_{50}$ of $P$. halepensis is greater than $2000 \mathrm{mg} / \mathrm{kg}$.

\section{Discussion}

The aim of the presented work was a phytochemical analysis and an evaluation of antioxidant and antidiabetic activities of the aqueous and ethanolic extracts of $P$. halepensis. Both extracts showed significant levels of polyphenols, flavonoids and tannins. In addition, the ethanolic extract was rich in bioactive compounds compared to the aqueous extract. Previous work reported that $P$. halepensis had several bioactive molecules belonging to secondary metabolites such as polyphenols, flavonoids, tannins, and terpenoids (5,17-19,28). Moreover, according

Table 5. Effect of aqueous and ethanolic extract of the bark of $P$. halepensis and acarbose on AUC and G Max after hyperglycemia caused by starch administration in normo-glycemic rats

\begin{tabular}{lcc}
\hline & AUC $\left(\mathrm{mg} /\left(\mathbf{d L}{ }^{*} \mathrm{~h}\right)\right.$ & G Max $(\mathrm{mg} / \mathrm{dL})$ \\
\hline Control & $290.67 \pm 8.93^{\mathrm{c}}$ & $130.67 \pm 3.27^{\mathrm{c}}$ \\
Acarbose $(10 \mathrm{mg} / \mathrm{kg})$ & $217.08 \pm 23.81^{\mathrm{b}}$ & $87.17 \pm 6.52^{\mathrm{a}}$ \\
PHAE $(250 \mathrm{mg} / \mathrm{kg})$ & $208.83 \pm 9.13^{\mathrm{a}}$ & $87.33 \pm 5.50^{\mathrm{a}}$ \\
PHAE $(500 \mathrm{mg} / \mathrm{kg})$ & $199.88 \pm 10.28^{\mathrm{a}}$ & $84.33 \pm 5.75^{\mathrm{a}}$ \\
PHEE $(250 \mathrm{mg} / \mathrm{kg})$ & $203.79 \pm 7.32^{\mathrm{a}}$ & $87.17 \pm 5.64^{\mathrm{a}}$ \\
PHEE $(500 \mathrm{mg} / \mathrm{kg})$ & $195.46 \pm 10.51^{\mathrm{a}}$ & $83.17 \pm 4.07^{\mathrm{a}}$ \\
\hline
\end{tabular}

Abbreviations: G Max, maximum blood sugar level; AUC, area under the curve; PHAE, $P$. halepensis aqueous extract; PHEE, $P$. halepensis ethanolic extract.

Different letters indicate the significant difference $(P<0.05)$ between aqueous extract, ethanolic extract and acarbose on the same column. Data are reported to mean $(n=3) \pm S D$. to the study by Kadri et al (29) made from the seeds of $P$. halepensis (Algerian pine), the total polyphenol contents found in the methanolic extract (50\%) was $3.71 \mathrm{mg}$ EAG/g of extract. This value is lower than that obtained in our study. However, Lantto et al (30) revealed a high content of total phenols (266 mg EAG/gE) in the acetone extract of the seeds of $P$. halepensis.

Pharmacological research on medicinal plants is always limited by the toxicological aspect of these plants. After the phytochemical study of the bark of P. halepensis, a toxicological study using acute oral toxicity in animals was performed to demonstrate the safety of $P$. halepensis extracts. The results of the acute oral toxicity limit test showed the total safety of the bark of $P$. halepensis with an estimated lethal dose $50\left(\mathrm{LD}_{50}\right)$ greater than $2 \mathrm{~g} / \mathrm{kg}$.

The bark of $P$. halepensis is used by herbalists and traditional healers in the treatment of some diseases including burns $(2,31)$. The wide use of bark in traditional medicine confirms the results obtained in our toxicological study. This demonstrated that $P$. halepensis did not exhibit toxicity and should therefore be exploited as a promising source for identifying pharmacological bioactive compounds.

Oxidative stress is strongly implicated without the genesis of type 2 diabetes. Indeed, it plays an important role in the establishment of a state of imbalance in the regulation of blood glucose $(32,33)$. The antioxidant effect was evaluated in vitro by three complementary tests, namely DPPH, FRAP and ABTS tests. Both extracts exhibited important antioxidant activities, in particular the ethanolic extract which reduced remarkably the tested radicals. Since we used other extract types of $P$. halpensis, our results were not completely similar to those indicated in the literature $(5,9,18)$. Indeed, Bouyahya et al showed very important antioxidant effects of volatile substances extracted from $P$. halepensis from northern Morocco (5). In addition, Meziti et al (18) have also demonstrated that the methanolic extract of $P$. halepensis had significant 
antiradical activity. The difference between the results found is certainly related to the composition of the extracts tested which are behind the antioxidant effects. Moreover, antioxidant molecules can help importantly the treatment of diabetes. Indeed, oxidative stress is involved in the genesis of diabetes and the use of natural antioxidant molecules constitutes and promising strategy for diabetes prevention $(32,33)$.

In addition, the absorption of carbohydrates in the intestine plays an important role in the homeostasis of blood glucose. Indeed, $\alpha$-amylase and $\alpha$-glucosidase are two enzymes involved in the degradation of complex sugars into simple sugars. Inhibition of these enzymes decreases significantly the glucose level and may be an effective strategy for the treatment of hyperglycemia using natural products. In this way, the inhibitory activity of the extracts of $P$. halepensis against $\alpha$-amylase and $\alpha$-glucosidase was tested. The results showed that the ethanolic extract has an important inhibitory effect against both enzymes compared to the aqueous extract. These results exceed the effect shown by acarbose used as a positive control. To our knowledge, no study has been carried out for the antidiabetic properties of $P$. halepensis, and this is the first study that highlights the inhibitory effects of the ethanolic and aqueous extract of $P$. halepensis. In addition, several studies have shown that Moroccan plants possesses antienzymatic properties against the enzymes involved in the degradation of sugars in the intestine $(34,35)$. However, these studies remain in vitro investigations and do not accurately represent an in vivo drug effect. Thus, in our study, we also tested antidiabetic effects in vivo using the glucose tolerance test and the starch tolerance test. The results revealed that the extracts did not have a significant effect on the decrease in blood glucose concentration compared to Metformine (drug used in OGTT). On the contrary, the extracts, especially the ethanolic extract, showed remarkable effects in the starch tolerance test comparing to Acarbose. This shows that the antidiabetic activities of $P$. halepensis extracts are essentially dedicated by enzymatic inhibition. The results of the in vivo tests confirm those of in vitro enzymatic inhibition and show that $P$. halepensis contain bioactive substances exhibiting high antidiabetic power.

\section{Conclusion}

Both ethanolic and aqueous extracts of $P$. halepensis presented important effects with OSTT assay, while they showed significant antidiabetic effects in OGTT assay. These findings suggest that the antidiabetic activity is only mediated by the inhibition of digestive enzymes. The results of this study showed that $P$. halepensis extracts possessed important antioxidant and antidiabetic effects. The antidiabetic effects are related to the inhibition of enzymes implicated in sugar metabolism. Moreover, antioxidant effects of $P$. halepensis can also be useful to improve the management of people with diabetes. All these results suggest that $P$. halepensis possesses several bioactive compounds which exhibit important antioxidant and antidiabetic effects. However, further investigations regarding the isolation of these main compounds and evaluation of their antioxidant and antidiabetic activities are needed.

\section{Authors' contributions}

NS conducted the experimentations, designed the analysis, and wrote a part of the manuscript. ME and OE contributed to animal experimentations. MEAF, YC and $\mathrm{AZ}$ conceived and supervised the study. $\mathrm{AB}$ analyzed the results, wrote the manuscript, and reviewed the final version. IB wrote a part of the manuscript and reviewed the final version. All read and confirmed the final version of manuscript for publication.

\section{Conflict of interests}

The authors have no conflicts of interest to declare.

\section{Ethical considerations}

Animal care and experiments were performed in accordance with the guidelines for the care and use of Laboratory of Pharmacology of the Faculty of Medicine and Pharmacy, Rabat, Morocco.

\section{Funding/Support}

This study did not receive any funding.

\section{References}

1. Aragones D, Rodriguez-Galiano VF, Caparros-Santiago JA, Navarro-Cerrillo RM. Could land surface phenology be used to discriminate Mediterranean pine species? Int J Appl Earth Obs Geoinf. 2019;78:281-94. doi: 10.1016/j.jag.2018.11.003.

2. Salhi N, Bouyahya A, Fettach S, Zellou A, Cherrah Y. Ethnopharmacological study of medicinal plants used in the treatment of skin burns in occidental Morocco (area of Rabat). S Afr J Bot. 2019;121:128-42. doi: 10.1016/j.sajb.2018.10.038.

3. El Hamsas El Youbi A, Ouahidi I, El Mansouri L, Daoudi A, Bousta D. Ethnopharmacological survey of plants used for immunological diseases in four regions of Morocco. European J Med Plants. 2016;13(1):1-24. doi: 10.9734/ ejmp/2016/12946.

4. Bouyahya A, Abrini J, Et-Touys A, Bakri Y, Dakka N. Indigenous knowledge of the use of medicinal plants in the North-West of Morocco and their biological activities. Eur J Integr Med. 2017;13:9-25. doi: 10.1016/j.eujim.2017.06.004.

5. Bouyahya A, Belmehdi O, Abrini J, Dakka N, Bakri Y. Chemical composition of Mentha suaveolens and Pinus halepensis essential oils and their antibacterial and antioxidant activities. Asian Pac J Trop Med. 2019;12(3):117-22. doi: 10.4103/1995-7645.254937.

6. Minervini F, Missaoui J, Celano G, Calasso M, Achour L, Saidane D, et al. Use of Autochthonous Lactobacilli to Increase the Safety of Zgougou. Microorganisms. 2019;8(1):29. doi: 10.3390/microorganisms8010029.

7. Mohamed AA, Behiry SI, Ali HM, EL-Hefny M, Salem MZM, Ashmawy NA. Phytochemical compounds of branches from P. halepensis oily liquid extract and S. terebinthifolius essential oil and their potential antifungal activity. Processes. 
2020;8(3):330. doi: 10.3390/pr8030330.

8. 8 Kadri N, Khettal B, Adjebli A, Cresteil T, Yahiaoui-Zaidi R, Barragan-Montero V, et al. Antiangiogenic activity of neutral lipids, glycolipids, and phospholipids fractions of Pinus halepensis Mill. seeds. Ind Crops Prod. 2014;54:6-12. doi: 10.1016/j.indcrop.2013.12.051.

9. Abbou A, Kadri N, Debbache N, Dairi S, Remini H, Dahmoune F, et al. Effect of precipitation solvent on some biological activities of polysaccharides from Pinus halepensis Mill. seeds. Int J Biol Macromol. 2019;141:663-70. doi: 10.1016/j.ijbiomac.2019.08.266.

10. Wang T, Li Q, Bi K. Bioactive flavonoids in medicinal plants: structure, activity and biological fate. Asian J Pharm Sci. 2018;13(1):12-23. doi: 10.1016/j.ajps.2017.08.004.

11. Devanesan AA, Zipora T, G. Smilin BA, Deviram G, Thilagar S. Phytochemical and pharmacological status of indigenous medicinal plant Pedalium murex L. $-\mathrm{A}$ review. Biomed Pharmacother. 2018;103:1456-63. doi: 10.1016/j. biopha.2018.04.177.

12. Rastall RA, Moreno FJ, Hernandez-Hernandez O. Editorial: dietary carbohydrate digestibility and metabolic effects in human health. Front Nutr. 2019;6:164. doi: 10.3389/ fnut.2019.00164.

13. Sinan KI, Zengin G, Zheleva-Dimitrova D, Etienne OK, Fawzi Mahomoodally M, Bouyahya A, et al. Qualitative phytochemical fingerprint and network pharmacology investigation of Achyranthes aspera Linn. extracts. Molecules. 2020;25(8). doi: 10.3390/molecules 25081973.

14. Tohma H, Altay A, Köksal E, Gören AC, Gülçin İ. Measurement of anticancer, antidiabetic and anticholinergic properties of sumac (Rhus coriaria): analysis of its phenolic compounds by LC-MS/MS. J Food Meas Charact. 2019;13(2):1607-19. doi: 10.1007/s11694-019-00077-9.

15. Eruygur N, Koçyiğit UM, Taslimi P, Ataş M, Tekin M, Gülçin İ. Screening the in vitro antioxidant, antimicrobial, anticholinesterase, antidiabetic activities of endemic Achillea cucullata (Asteraceae) ethanol extract. S Afr J Bot. 2019;120:141-5. doi: 10.1016/j.sajb.2018.04.001.

16. Bouyahya A, Belmehdi O, El Jemli M, Marmouzi I, Bourais I, Abrini J, et al. Chemical variability of Centaurium erythraea essential oils at three developmental stages and investigation of their in vitro antioxidant, antidiabetic, dermatoprotective and antibacterial activities. Ind Crops Prod. 2019;132:111-7. doi: 10.1016/j.indcrop.2019.01.042.

17. Benouadah N, Aliouche D, Pranovich A, Willför S. Chemical characterization of Pinus halepensis sapwood and heartwood. Wood Mater Sci Eng. 2019;14(3):157-64. doi: 10.1080/17480272.2018.1448436.

18. Meziti H, Bouriche H, Kada S, Demirtas I, Kizil M, Senator A. Phytochemical analysis, and antioxidant, anti-hemolytic and genoprotective effects of Quercus ilex L. and Pinus halepensis Mill. methanolic extracts. J Pharm Pharmacogn Res. 2019;7(4):260-72.

19. Kotroni E, Simirioti E, Kikionis S, Sfiniadakis I, Siamidi A, Karalis V, et al. In vivo evaluation of the anti-inflammatory activity of electrospun micro/nanofibrous patches loaded with Pinus halepensis bark extract on hairless mice skin. Materials (Basel). 2019;12(16). doi: 10.3390/ma12162596.

20. Mitić ZS, Jovanović B, Jovanović SČ, Stojanović-Radić ZZ, Mihajilov-Krstev T, Jovanović NM, et al. Essential oils of Pinus halepensis and P. heldreichii: chemical composition, antimicrobial and insect larvicidal activity. Ind Crops Prod.
2019;140:111702. doi: 10.1016/j.indcrop.2019.111702.

21. Singleton VL, Orthofer R, Lamuela-Raventós RM. Analysis of total phenols and other oxidation substrates and antioxidants by means of folin-ciocalteu reagent. Methods Enzymol. 1999;299:152-78. doi: 10.1016/s0076-6879(99)99017-1.

22. Dewanto V, Wu X, Liu RH. Processed sweet corn has higher antioxidant activity. J Agric Food Chem. 2002;50(17):495964. doi: 10.1021/jf0255937.

23. Julkunen-Tiitto R. Phenolic constituents in the leaves of northern willows: methods for the analysis of certain phenolics. J Agric Food Chem. 1985;33(2):213-7. doi: 10.1021/jf00062a013.

24. Huang B, Ke H, He J, Ban X, Zeng H, Wang Y. Extracts of Halenia elliptica exhibit antioxidant properties in vitro and in vivo. Food Chem Toxicol. 2011;49(1):185-90. doi: 10.1016/j. fct.2010.10.015

25. Tuberoso CI, Boban M, Bifulco E, Budimir D, Pirisi FM. Antioxidant capacity and vasodilatory properties of Mediterranean food: the case of Cannonau wine, myrtle berries liqueur and strawberry-tree honey. Food Chem. 2013;140(4):686-91. doi: 10.1016/j.foodchem.2012.09.071.

26. Oyaizu M. Studies on products of browning reaction-antioxidative activities of products of browning reaction prepared from glucosamine. The Japanese Journal of Nutrition and Dietetics. 1986;44(6):307-15. doi: 10.5264/ eiyogakuzashi.44.307.

27. Tadera K, Minami Y, Takamatsu K, Matsuoka T. Inhibition of alpha-glucosidase and alpha-amylase by flavonoids. J Nutr Sci Vitaminol (Tokyo). 2006;52(2):149-53. doi: 10.3177/ jnsv.52.149.

28. Mouhajir F, Hudson JB, Rejdali M, Towers GHN. Multiple antiviral activities of endemic medicinal plants used by Berber peoples of Morocco. Pharm Biol. 2001;39(5):364-74. doi: $\quad$ 10.1076/phbi.39.5.364.5892.

29. Kadri N, Khettal B, Adjebli A, Cresteil T, Yahiaoui-Zaidi R, Barragan-Montero V, et al. Antiangiogenic activity of neutral lipids, glycolipids, and phospholipids fractions of Pinus halepensis Mill. seeds. Ind Crops Prod. 2014;54:6-12. doi: 10.1016/j.indcrop.2013.12.051.

30. Lantto TA, Dorman HJD, Shikov AN, Pozharitskaya ON, Makarov VG, Tikhonov VP, et al. Chemical composition, antioxidative activity and cell viability effects of a Siberian pine (Pinus sibirica Du Tour) extract. Food Chem. 2009;112(4):936-43. doi: 10.1016/j.foodchem.2008.07.008.

31. Boulâacheb N. Traditional use of resin of Pinus halepensis Mill. by the people of Kabylia (Algeria, North Africa). Acta Hortic. 2010;(853):435-8.

32. Maritim AC, Sanders RA, Watkins JB, 3rd. Diabetes, oxidative stress, and antioxidants: a review. J Biochem Mol Toxicol. 2003;17(1):24-38. doi: 10.1002/jbt.10058.

33. West IC. Radicals and oxidative stress in diabetes. Diabet Med. 2000;17(3):171-80.doi:10.1046/j.1464-5491.2000.00259.x.

34. Fettach S, Mrabti HN, Sayah K, Bouyahya A, Salhi N, Cherrah Y, et al. Phenolic content, acute toxicity of Ajuga iva extracts and assessment of their antioxidant and carbohydrate digestive enzyme inhibitory effects. S Afr J Bot. 2019;125:3815. doi: 10.1016/j.sajb.2019.08.010.

35. El Omari N, Sayah K, Fettach S, El Blidi O, Bouyahya A, Faouzi MEA, et al. Evaluation of in vitro antioxidant and antidiabetic activities of Aristolochia longa extracts. Evid Based Complement Alternat Med. 2019;2019:7384735. doi: $10.1155 / 2019 / 7384735$. 